\title{
Macunaíma em quadrinhos: aspectos estéticos modernistas na rapsódia gráfico-visual antropofágica
}

\author{
Ricardo Oliveira de Freitas \\ https://orcid.org/0000-0002-7528-4488 \\ Lucineide Magalhães de Matos" \\ https://orcid.org/0000-0002-9105-2863 \\ I - UNEB. \\ Salvador (BA), Brasil \\ II - UFF. \\ Niterói (RJ), Brasil
}

Resumo: Analisamos a obra Macunaíma em quadrinhos (2016), de autoria de Angelo Abu e Dan X, concentrando-nos na análise acerca da (re) apresentação do modernismo no interior da história em quadrinhos (HQ). Consideramos os signos indiciais do projeto modernista, como apresentado na prosa de Mário de Andrade, presentes na HQ. Por isso, optamos, como referencial teórico-metodológico, por realizar uma leitura Intersemiótica da obra, que coloca em jogo os dois principais signos nela existentes: verbal e visual. Com base na Teoria Intersemiótica, interpretamos a HQ como uma tradução entre signos, capaz de trazer para o campo da visualidade argumentos modernistas diversos, para além do que encontramos na prosa andradiana. Defendemos que Macunaíma em quadrinhos é uma rapsódia gráficovisual antropofágica, perfilhada por índices como cores e traços estilísticos, que colocam em evidência o modernismo do século XX, assim como o verbal e o visual em interação na $\mathrm{HQ}$.

Palavras-chave: histórias em quadrinhos; tradução intersemiótica; modernismo; antropofagia.

Abstract: Macunaíma in comics: modernist aesthetic aspects in an anthropophagic graphic-visual rhapsody - We analyze the comic book Macunaíma em quadrinhos (2016), by Angelo Abu and Dan X, concentrating on the analysis of the (re) presentation of modernism within comics. We consider the signs indicative of the modernist project, as presented in Mário de Andrade's prose, which appears in the comics. Therefore, we chose, as a theoretical-methodological reference, to perform an Intersemiotic reading of the comics, which puts into play the two main signs that exist: verbal and visual. Based on the Intersemiotic Theory, we interpret Macunaíma 
em quadrinhos as a translation between signs, capable of bringing to the field of visuality a lot of modernist arguments, beyond what we found in the Andradian prose. We argue that Macunaíma em quadrinhos is an anthropophagic graphic-visual rhapsody, based on indices such as arts, colors and stylistic traits, which highlight twentieth-century modernism.

Keywords: comics; intersemiotic translation; modernism; anthropophagy.

\section{Introdução}

No texto ora apresentado, desenvolvemos análise sobre a HQ Macunaíma em quadrinhos (2016), homônima da rapsódia Macunaíma: um herói sem nenhum caráter (1928), de autoria de Mário de Andrade, que recebeu tradução intersemiótica pelas mãos dos quadrinistas e ilustradores Angelo Abu e Dan X. Definimos que não faríamos uma análise comparativa entre o texto-fonte e a tradução. Optamos por empreender leitura e interpretação dos quadrinhos como objeto analítico em função da gama de conteúdos e temas articulados em seu interior. Alguns desses conteúdos são velhos conhecidos das análises empreendidas sobre a prosa, que ganham novo fôlego e vigor a partir dos seus usos junto à tradução imagética. Tal fato confere à HQ Macunaíma em quadrinhos uma qualificação que se distancia da mera adaptação, já que revela a preocupação de seus idealizadores em realizar um projeto gráfico inovador, que coloca em pauta a base contextual e motivadora do texto de Mário de Andrade (qual seja, o Modernismo brasileiro), mas que não se restringe a esta.

Considerando que o texto assume o compromisso de revelar a contribuição da narrativa Macunaíma em quadrinhos para a manutenção do projeto modernista, interessanos revelar o modo com que o discurso modernista se expande em seu interior, através de elementos estéticos articulados, como as cores, a intersecção entre linguagens, os traços dos desenhos e a composição gráfica da HQ. Por tudo isso, entendemos que a HQ aqui analisada é uma rapsódia gráfico-visual antropofágica, onde se percebe, desde seu planejamento, o ato de 'mastigar' o texto verbal, assim como seu contexto, para, em seguida, degluti-los em formato imagético.

Vale ressalvar, ainda, a preservação do caráter de rapsódia ${ }^{1}$, mesmo que a narrativa seja apresentada no formato gráfico-visual. Com isso, mantém-se o caráter antropofágico da obra. Tomando em empréstimo as palavras dos autores da HQ: "Depois de muito ler e destrinchar a palavra escrita, os compadres limpavam toda a banha da Pacuera, rabiscaram bem tudo que estava por vir, e desenhavam em cima, e pintavam e rasgavam e deixavam sangrar" (ABU; X, 2016, p. 76). Trata-se, como preferem os autores, de uma Antropofagofagia, onde signos visuais e verbais agem em interação na contação da história do herói brasileiro.

1 Termo que faz referência a obras gregas, a exemplo da llíada e Odisseia, e que são caracterizadas por narrativas que remetem a mitos folclóricos e lendas populares, reunindo, assim, uma linguagem popular próxima à realidade de um povo. 
A base metodológica da nossa análise repousa na Tradução Intersemiótica, apresentada no interior dos estudos semióticos - o que nos permite articular, adequadamente, o texto verbo-visual como uma tradução intersígnica, a partir da qual as instâncias do verbal e do visual agem em interação. A intersemiótica tem servido como base argumentativa promissora, sobretudo, nas histórias em quadrinhos, uma vez que as HQs articulam o jogo de interação entre signos, ao inserirem em seus quadros palavras e imagens. Em Macunaíma em quadrinhos, os autores realizam um processo de decupagem da prosa, escolhendo quais conteúdos verbais serão legendados, quais surgirão como falas nos balões e quais serão traduzidos para a esfera visual (corriqueiramente relacionada à linguagem quadrinística).

Vale ressaltar que, nesse texto, discutimos a representação do conteúdo modernista em Macunaíma em quadrinhos de modo desprovido de qualquer preconceito em relação à $\mathrm{HQ}$ traduzida de um texto literário. Isto nos possibilita olhar a obra como um produto que apresenta o elemento literário intrínseco, não sendo preciso, portanto, complexificar essa relação. Esperamos contribuir para os estudos que veem as histórias em quadrinhos como recursos de representação estética e de transformação de textos literários em artes visuais, o que somente reforça a importância dos textos-fontes. Defendemos que o cânone, nas HQs, é repensado e rearticulado a partir de um processo de transcriação que abrange diversos campos, além do literário, como veremos em Macunaíma em quadrinhos.

\section{A Tradução Intersemiótica}

As HQs constituem um sistema de linguagem capaz de produzir representação, ao apresentarem o princípio de interação entre o signo verbal e o signo visual. Na contemporaneidade, os espaços de comunicação e representação deixaram de operar a partir da ideia binária de oposição entre texto e imagem, muito em função das distintas linguagens que emergiram com base na escrita e no desenvolvimento tecnológico. $\mathrm{Na}$ Antiguidade, suportes como o papiro, o pergaminho e o nosso conhecido livro cumpriram a função de afirmar o discurso verbal (falado e escrito) como principal forma de transmissão de mensagens, o que, todavia, não significava privilégio ou exclusivismo da linguagem verbal (SANTAELLA, 2012). Tanto assim que, com o avanço em tecnologias, desde o telégrafo até a Internet, passando pela fotografia, rádio, cinema, televisão, telefone e pelos quadrinhos, diferentes linguagens (escrita, sonora e imagética) passaram a coexistir com a linguagem verbal e, como consequência, a produzir combinações de linguagens múltiplas entre o som, a imagem e o texto.

Com base nos estudos semióticos e reconhecendo a possibilidade de diálogos promovidos pela interseção entre uma pluralidade de linguagens, a Teoria da Tradução Intersemiótica se apresenta, para nós, como aporte acertado, já que envolve dois pontos centrais: a semiótica, enquanto campo de estudo da linguagem, e a ideia de tradução entre signos. A partir desses dois pontos, construímos a tríade ícone/índice/símbolo pelo fato de entendermos que esses três elementos se constituem com os principais tipos 
de signos. Também acreditamos que os três signos nos permitem articular, de modo particular, o processo de "semiose (ação do signo) como transformação de signos em signos" (PLAZA, 2003, p. 17).

Desse modo, defendemos a passagem de um signo (verbal) para outro (visual) revelando, assim, uma tradução intersemiótica de Macunaíma em prosa para Macunaíma em quadrinhos, num tipo de tradução intersígnica. Realizar a leitura da ligação entre o icônico e o verbal e dos sentidos e significados propostos por esta ligação é, portanto, a proposta do texto. Para tanto, partimos das histórias em quadrinhos como constituintes de linguagem peculiar. Naquilo que cabe de vinculação com os quadrinhos, apresentamos o princípio básico de interpretação dos signos recobrando o pensamento peirceniano do signo em suas relações triádicas (PIGNATARI, 2004; PLAZA, 2003).

Diferente da tradução interlingual e da intralingual, a tradução intersemiótica envolve distintos signos em seu processo, inclusive os signos verbais, podendo mesmo abranger os dois tipos de tradução anteriores articulados numa mesma mensagem. Sendo assim, é possível concluir que esta última operação de tradução se concentra nas formas estéticas que as diversas linguagens promovem, como bem destaca Plaza (2003):

\begin{abstract}
Na Tradução Intersemiótica como transcriação de formas o que se visa é penetrar pelas entranhas dos diferentes signos, buscando iluminar suas relações estruturais, pois são essas relações que mais interessam quando se tratam de focalizar os procedimentos que regem a tradução. Traduzir criativamente é, sobretudo, interligar estruturas que visam à transformação de formas. (PLAZA, 2003, p. 71).
\end{abstract}

Conclui-se, então, que adaptações de clássicos da literatura para os quadrinhos podem ser lidas pela via da Teoria da Tradução Intersemiótica, tanto no nível das formas estéticas, quanto das linguagens envolvidas nessas traduções. Aliás, linguagens distintas tendem a se interconectar nos quadrinhos, em movimento de interação entre o verbal e o visual, evidenciando o modo com que uma história é narrada a partir da HQ.

Um texto verbal, ao ser traduzido para outra linguagem, deve levar em conta os suportes onde essas linguagens estão fixadas, assim como os códigos ou signos que lhe são peculiares. Nesse sentido, Plaza destaca: "Passado-presente-futuro estão atravessados pelas antigas e novas formas tecnológicas" (PLAZA, 2003, p. 11). E como as linguagens se transformam, acabam se decompondo em formas e formatos mais próximas à realidade do leitor, como acontece com os livros impressos, agora disponíveis em formato PDF, a partir de (outras e novas) plataformas tecnológicas como o tablet, o notebook ou o smartphone. Esse processo também ocorre com as HQs, atualmente disponíveis em versões on-line e em formato de e-book. 


\section{Os sentidos da antropofagia na literatura}

Raul Bopp (2012) evidencia a evolução da arte moderna nas primeiras décadas do século XX como um evento consequente ao progresso econômico e tecnológico, naquele momento, em pauta em todo o mundo. A arte, não diferente de outros campos, sofre influência das mudanças sociais, culturais, econômicas e estruturais, refletindo em formas novas de pensar sobre sua própria estética. Como em outros países, o Brasil observou a emergência de uma revolução artística e cultural peculiar, com a eclosão do Movimento Modernista Brasileiro, que teve como marco fundador a Semana de Arte Moderna. O evento, realizado em São Paulo, em fevereiro de 1922, no auge das transformações políticas, econômicas e sociais que assolavam o país, resultou num movimento vanguardista que apresentava novas formas de expressões artísticas e culturais (com destaque para a produção literária), que apresentavam como tendência a valorização da identidade nacional e suas nuances.

No interior do Modernismo, a Antropofagia surgiu como artifício a partir do qual era tecida a identidade artístico-literária, trazendo, como desdobramento para o campo da literatura, autores e textos que ditavam o nacionalismo modernista, a exemplo de Mário de Andrade e sua obra seminal Macunaíma: o herói sem nenhum caráter. A obra surge no apogeu do Modernismo brasileiro como um divisor na literatura nacional, uma antítese ao parnasianismo e naturalismo dos textos, ao ofertar um tipo de escrita onde os faits divers (vários fatos) e a anedota são características marcantes, como aponta Alfredo Bosi (2003). Algo, diga-se de passagem, similar aos quadrinhos. Tornou-se, segundo Gilda de Melo (2003, p. 9), "o livro mais importante do nacionalismo modernista brasileiro".

O personagem central "Macunaíma" pode ser classificado como anti-herói, já que não se enquadra nas construções do romance nacional de influência eurocêntrica, onde o herói é romantizado e idealizado a partir de características europeias, como acontece no Romantismo. Pelo contrário, suas marcas são a malandragem e a falta de caráter, ou melhor, de um caráter em formação. Assim, na obra se reconhece um herói brasileiro "modelado em resíduos folclóricos" (BOPP, 2012, p. 51). Uma síntese com tonalidade nacional materializada através de um texto em prosa, antológico e marcadamente antropofágico, ou seja, uma rapsódia à brasileira.

Macunaíma, a prosa e o personagem-título, apresenta-se de forma híbrida tanto pela construção de sua narrativa, quanto pela elucidação de seus personagens, refletindo, claramente, o discurso antropofágico-modernista. A história do herói, todavia, rompeu com os limites do texto andradiano em prosa, conferindo à narrativa traduções para uma multiplicidade de formatos.

Em 1943, o artista plástico Carybé desenhou ilustrações da rapsódia em bico-depena. No final da década de 1970, seus desenhos foram reunidos no livro Macunaíma, ilustrações do mundo do herói sem nenhum caráter (1978). O livro apresentava imagens 
que contavam a história em capítulos, através de um discurso sequenciado, como na obra de referência, todavia, sem a presença de texto, se aproximando da ideia de livro ilustrado, em função de haver um sistema narrativo baseado em imagens que demarcavam, assim, a prevalência da linguagem visual. Ainda em termos de produção visual, em 1956, Tarsila do Amaral cria o Batizado de Macunaíma, aonde é retratada a cerimônia de batismo do personagem-título da rapsódia de Mario de Andrade (AMARAL, 1956).

Na dinâmica verbo-visual, o filme Macunaíma, de Joaquim Pedro de Andrade, foi para as telas do cinema em 1969, lançado como gênero de comédia. Grande Otelo e Paulo José destacaram-se na obra audiovisual como intérpretes do herói brasileiro.

A história em quadrinhos de Angelo Abu e Dan X é lançada no século seguinte, em 2016, apresentando a rapsódia a partir da linguagem quadrinística. Na HQ há referências aos traços pictóricos de Carybé, de Tarsila do Amaral e de Anita Malfatti, revelando a intersecção verbo-visual, portanto, intersemiótica, e a proposta modernista de Mário de Andrade, pelo olhar dos roteiristas e ilustradores Angelo Abu e Dan X.

\section{A 'Antropofagofagia' de Ângelo Abu e Dan X}

Para revelar o processo criativo de Macunaíma em quadrinhos, ao invés de optarmos por uma metodologia de entrevistas com os criadores, escolhemos apresentá-lo a partir do posfácio da obra, feito, igualmente, em formato de histórias em quadrinhos, por Angelo Abu e Dan X. Assim o fazemos, por entendermos que o desfecho da obra oferece as bases necessárias à compreensão das formulações de ideias, bem como por ser esta uma forma original de explicar os lugares visitados pelos autores para a composição da HQ. Portanto, começamos a entender a obra em seu sentido inverso, ou seja, de trás para frente, revelando, na narrativa em quadros, uma Antropofagofagia. Boa ilustração encontra-se na primeira página do posfácio da HQ Macunaíma (Fig. 1)².

2 Agradecemos à Editora Peirópolis, que nos concedeu, gentilmente, a autorização de uso das imagens disponibilizadas nesse texto. 


\section{POSFACIO}

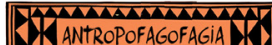

UMA FEITA ABU ESTAVA COM MUITA FOME, NÃO HAVIA COMIDA NO MOCAMBO E ELE ESTAVA COM UMA BAITA DUMA PREGUICA DE SAIR PRA CACAR. TAMBÉM NÃO QUERIA PESCAR NEM ARMAR ARAPUCA PRA PRESA ALGUMA NÃO, NENHUMA DESSAS OBRIGACZES.
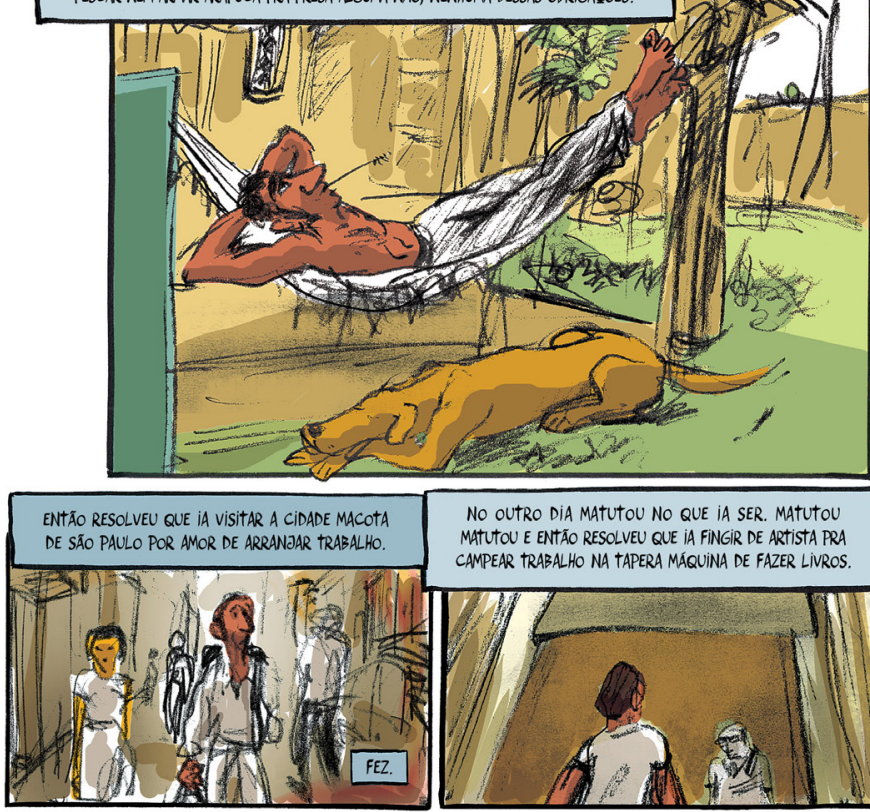

NO OUTRO DIA MATUTOU NO QUE IA SER. MATUTOU MATUTCU E ENTÃO RESOLVEU QUE IA FINGIR DE ARTISTA PRA CAMPEAR TRABALHO NA TAPERA MÁQUINA DE FAZER LIVROS

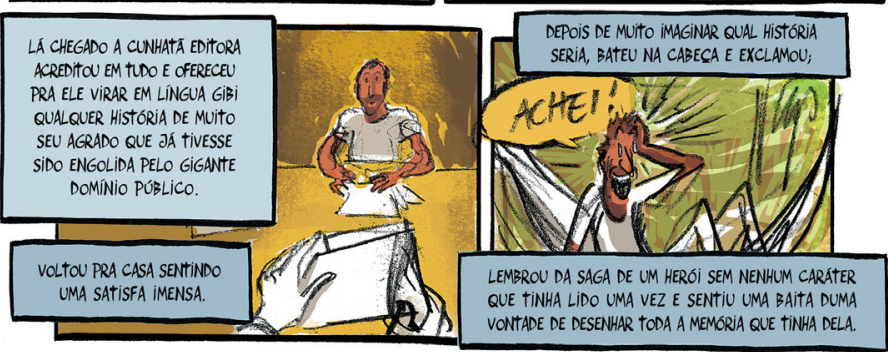

Fig. 1. Posfácio de Macunaíma em quadrinhos. Abu e X (2016, p. 73).

Ao que nos parece, o termo Antropofagofia, escolhido por Abu e X (2016), constitui artifício metafórico utilizado para a concepção da ideia da HQ. Pressupomos que se trata de uma reconfiguração da palavra escrita de Mário de Andrade, feita em boa parte através de metáforas. Assim, se Mário de Andrade se valeu da figura de linguagem, metáfora, para produzir a rapsódia, os autores da HQ o fazem realizando uma espécie de antropofagia ao quadrado, uma metantropofagia, destrinchando as palavras de Andrade e transmutando-as para o sistema imagético, através do que intitulam Antropofagofagia. 
Observando a Figura 1, distintas inferências podem ser assinaladas. A primeira, se refere ao fato de o ilustrador se fazer personagem na própria obra para contar o percurso de produção da HQ, desde a ideia original até a sua publicação. Abu é narrador-personagem da história. Outra interferência diz respeito à apropriação do discurso verbal da rapsódia através de marcadores linguísticos, como a ideia de preguiça, e das expressões populares, indicadas na fala de Macunaíma, como macota, matutar, campear e cunhatã. Exemplos não faltam. Abu surge no primeiro quadro deitado em uma rede e quase abaixo desta um cão a dormir. A partir da legenda, o narrador-personagem explica:

Uma feita Abu estava com muita fome, não havia comida no Mocambo e ele estava com uma baita duma preguiça de sair pra caçar. Também não queria pescar nem armar arapuca pra presa alguma não, nenhuma dessas obrigações. (ABU e X, 2016, p. 73).

A partir desse excerto, é possível concluir que Abu se aproxima intencionalmente do personagem Macunaíma ao indicar a ideia de preguiça e, assim como o herói, deixar sua "querência" em busca de trabalho. Abu chega a São Paulo, cidade que intitula macota, expressão popular utilizada para se referir a ideia da cidade em sua grandiosidade e riqueza.

Outro indicador peculiar da narrativa é a ideia de esperteza ou malandragem característica do personagem em semelhança com o herói brasileiro. Abu explica que "matutou", "matutou", sem saber o que fazer, até decidir "que ia fingir de artista pra campear trabalho na tapera maquina de fazer livros" (ibidem). Tapera corresponde à expressão utilizada por Mário de Andrade para definir uma habitação em ruína. Na rapsódia, o termo é utilizado pelo autor para revelar o estado em que se encontrava o antigo aldeamento de Macunaíma depois que ele deixou São Paulo. No posfácio da HQ, parece haver ideia similar, de algo antigo, quando Abu cita a "tapera máquina de fazer livros". Essa seria, portanto, uma máquina antiga, aonde são produzidos os livros.

"Lá chegando a cunhatã editora acreditou em tudo e ofereceu pra ele virar em língua gibi qualquer história de muito seu agrado que já tivesse sido engolida pelo gigante domínio público" (ibidem). Aqui, a editora aparece como cunhatã, termo de língua indígena, mais precisamente, tupi guarani, utilizado como substantivo feminino para referir-se à menina, à mulher. $\mathrm{O}$ termo tem sentido semelhante na obra de Andrade, quando o autor o utiliza para se referir às mulheres.

O narrador-personagem se vale, ainda, da estratégia de Macunaíma acerca da esperteza e da malandragem para conseguir trabalho. Tal feito gera nele imensa satisfação, ou, como prefere uma enorme "satisfa".

A denominação "gigante domínio público" evidencia comparação com o personagem Venceslau Pietro Pietra, o gigante algoz de Macunaíma. Isso é feito para deixar claro que a história a ser quadrinizada não poderia ter restrição de uso. Seguindo o jogo metafórico do posfácio, a obra deveria ter sido "engolida" pelo "gigante domínio público" para ser copiada sem a necessidade de licença da parte de quem possuísse seus direitos autorais. 
Macunaíma surge como necessidade e, também, como parte de um interesse pessoal de Angelo Abu, que se lembrou, segundo apontam as ilustrações da $H Q$, deitado na rede, "de um herói sem nenhum caráter que tinha lido uma vez e sentiu uma baita duma vontade de desenhar toda a memória que tinha dela" (ABU e X, 2016, p. 73). A partir disso, o autor dá início ao processo de pesquisa e criação da tradução. Abu descobriu, ainda, que o ano de 2015 marcava setenta anos da morte de Mário de Andrade (1893-1945). Significava que, a partir de janeiro de 2016², todas as suas obras estariam em domínio público, inclusive Macunaíma: o herói sem nenhum caráter. Igualmente através da metáfora, Abu destaca: “Dizem que pro tal gigante vir precisava esperar que os ipês de beira-rio relampeassem setenta vezes de novo de amarelo depois que o autor da história já estivesse bem morto" (ABU e X, 2016, p. 74). E com grande alegria, o narrador diz: "Ficou numa satisfa ainda maior quando fez as contas e calculou que faltavam só duas floridas pra completar o prazo". Calculando as floridas dos ipês, a ideia de traduzir a rapsódia teria surgido em 2013 e, desse ano até 2015, deu-se todo o processo de criação, culminado com a publicação do impresso em 2016. Nesse percurso, Abu tratou de envolver seu 'cumpadre' Dan X. O primeiro ato da dupla foi a criação do personagem central, lançando ideias como a distância entre o herói sem caráter da prosa e do filme de Joaquim Pedro de Andrade.

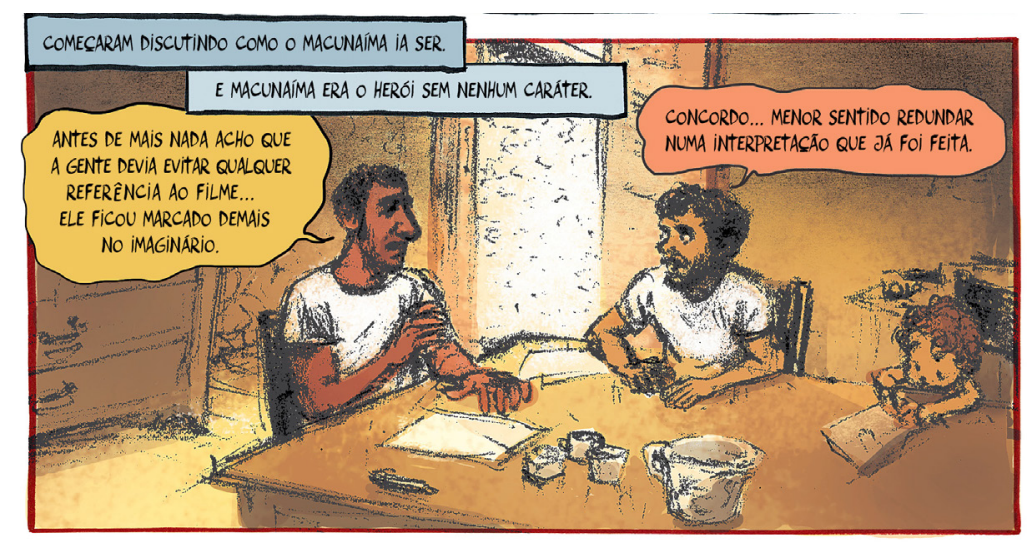

Fig. 2. Posfácio de Macunaíma em quadrinhos. Abu e X (2016, p. 74).

Assim ficaram os traços iniciais do piá Macunaíma.

3 Segundo a Lei de Direitos Autorais, de no 9.610, de 19 de fevereiro de 1998, em seu Artigo 41, "os di-reitos patrimoniais do autor perduram por setenta anos contados de $1^{\circ}$ de janeiro do ano subsequente ao de seu falecimento, obedecida a ordem sucessória da lei civil". 


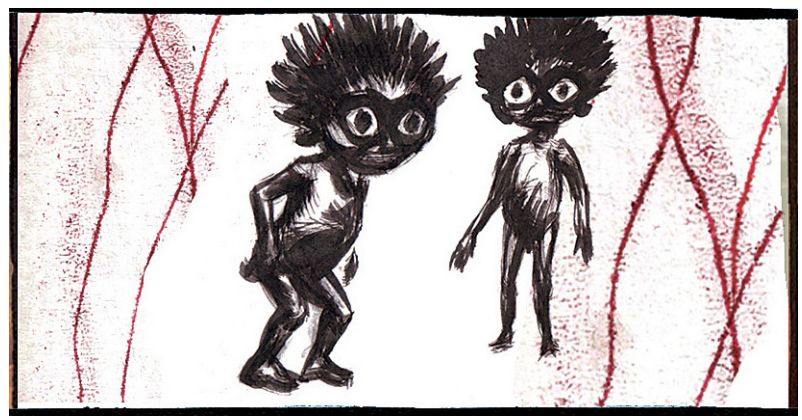

Fig. 3. Posfácio de Macunaíma em quadrinhos. Abu e X (2016, p. 75).

Era preto, de cabeça avantajada, com os olhos esbugalhados "que nem de sagui desmamado por amor de aguçar a carinha enjoada de piá" (ABU e X, 2016, p. 75). Mas, ainda carecia de ganhar mais corpo.

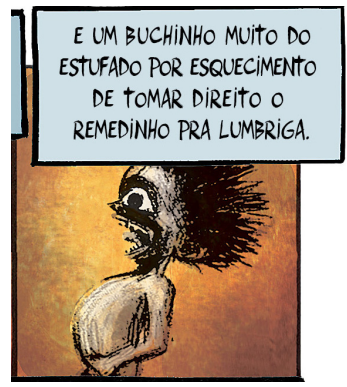

Fig. 4. Posfácio de Macunaíma em quadrinhos. Abu e X (2016, p. 75).

Precisava, ainda, de cor. Afinal, os quadrinhos seriam coloridos. Relembrando as escritas andradianas, Macunaíma "era preto retinto". Todavia, Abu e X (2016) foram compondo, sem intenção, tons mais azulados. Assim, Macunaíma ficaria retinto de azul.

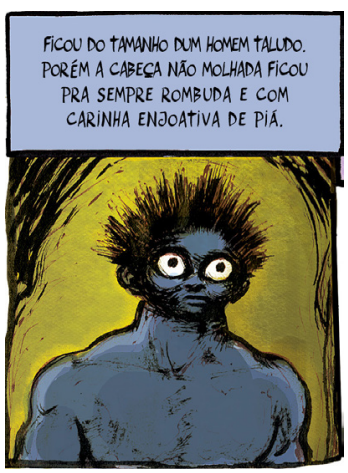

Fig. 5. Macunaíma em quadrinhos. Abu e X (2016, p. 20). 
Os autores da rapsódia gráfica logo perceberam a semelhança de cor entre o piá azul da sua HQ, "outro herói azul de nome Rama lá das bandas indiana do Oriente" (ABU e X, 2016, p. 75) e o Macunaíma do cinema. Aqui, entra em cena uma das principais distinções entre a HQ e o texto em prosa. Andrade apresenta seu texto baseado na categorização de raça, revelando os três matizes de referência no Brasil, a saber, o negro, o índio e o branco. Já nos quadrinhos, o destaque está na tentativa de "contrariar" a "divisão de raça cromada que a máquina governo tratou de inventar" (ibidem). Por isso, os personagens de Mário de Andrade nos quadrinhos assumem diversas tonalidades, "todos seriam muito retintos de piranga de urucum, uma de jenipapo, ajubá de girimum" (ibidem), isto é, vermelho como o urucum, negro, preto como a nódoa do jenipapo e branco como a madeira do jerimum. Todas retintas, em tons fortes.

Há uma profusão do uso das cores na HQ. É possível observar cores diversas como amarelo, vermelho, laranja, com destaque para a figura de Macunaíma, cuja cor se distingue das demais (azul retinto). A cor nas HQs é signo plástico constituinte da linguagem quadrinística, podendo operar como uma figura cinética, como, por exemplo, quando nos dá a sensação de movimento na cena ou destaca um personagem. Como explica Ramos (2016, p. 87) cores são "signos plásticos que contêm informação ora mais relevante para a compreensão do texto narrativo, ora menos. Mas sempre com conteúdo informacional e inserida no espaço do quadrinho, onde se passa a cena narrativa".

Além dessas funções, em Macunaíma em quadrinhos, a cor assume um papel mais amplo, ao fazer referência ao movimento modernista com seus traços coloridos. Assim, é o fator de colorização das personagens e das cenas que leva os ilustradores a dar, eles próprios, um primeiro passo no reconhecimento de sua obra como um produto de caráter modernista. "Acharam aquilo tudo muito modernista e deram uma grande gargalhada" (ABU e X, 2016, 75). Nesse ponto já se percebe a veia antropofágica da tradução quadro a quadro, o que fica mais evidente no quadro seguinte (Fig. 6). 


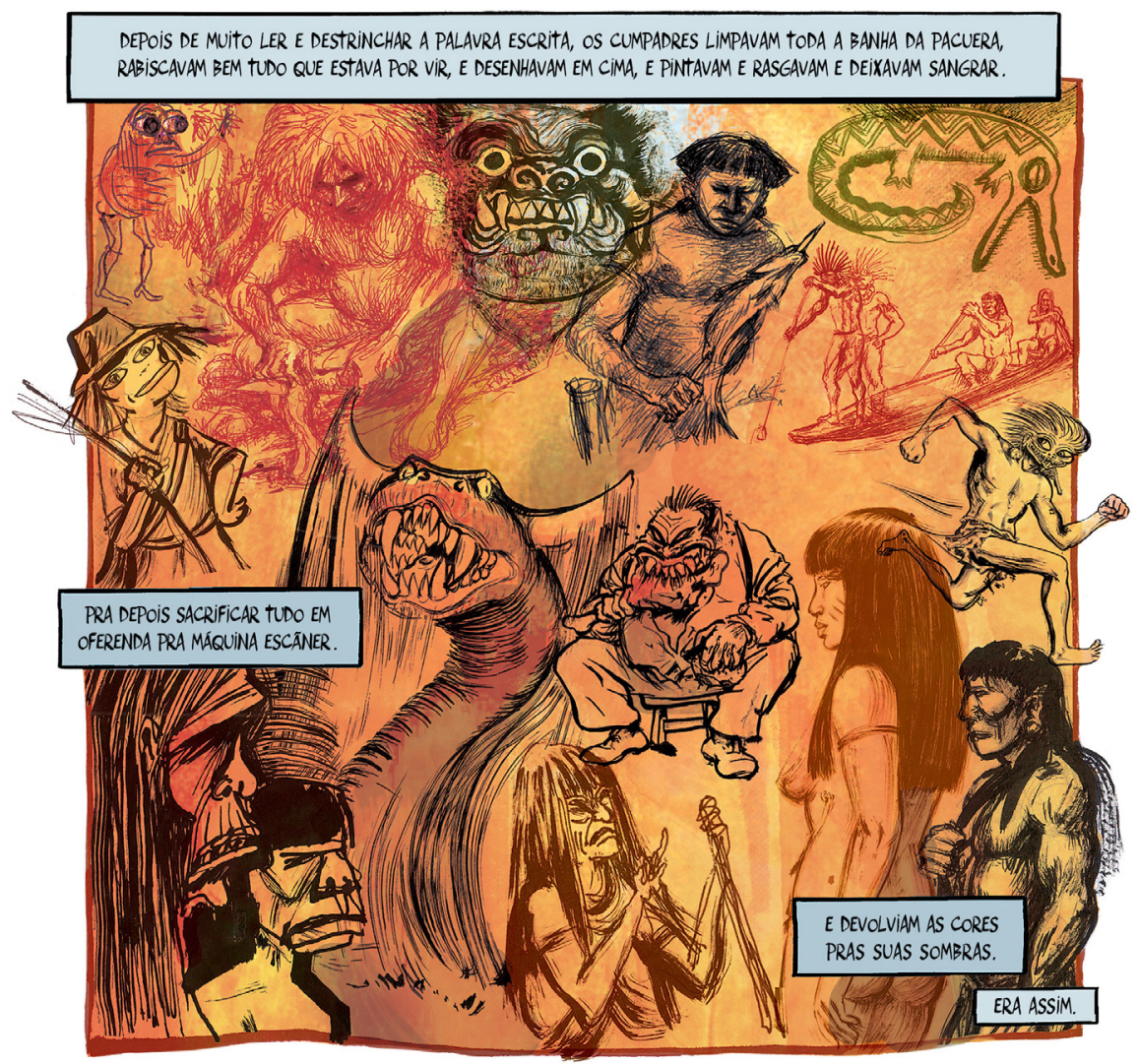

Fig. 6. Posfácio de Macunaíma em quadrinhos. Abu e X (2016, p. 76).

A metáfora Antropofagofagia, criada pelos autores, é confirmada nesse momento, quando se lê na legenda: "Depois de muito ler e destrinchar a palavra escrita, os compadres limpavam toda a banha da Pacuera, rabiscaram bem tudo que estava por vir, e desenhavam em cima, e pintavam e rasgavam e deixavam sangrar". (ABU e X, 2016, p. 76). Aproximando-se do discurso antropofágico, os autores mastigaram e deglutiram a obra andradiana para recompô-la a partir de outro formato, o imagético.

$\mathrm{Na}$ avidez das cores e das linhas desenhadas (Fig. 6), as personagens assumem formas e traços intensos, capazes de dar a impressão de um devorar constante, presente nas linhas em vermelho do curupira. Esse aparece tracejado em linhas vermelhas, no canto superior esquerdo do quadro, cortando parte de sua própria perna. Igual valor antropofágico, sugere o rosto monstruoso do gigante Vesceslau Pietro Pietra a devorar um avultado pedaço de carne. Mesma importância indica a figura em movimento da Boiúna, 
as expressões faciais de Jiguê e Maanape, assim como, as imagens de outros personagens no interior desse mesmo quadro

Outro argumento encontrado em vigor no prefácio é oferecido pelo narrador, quando aponta o espírito modernista em Abu e X.

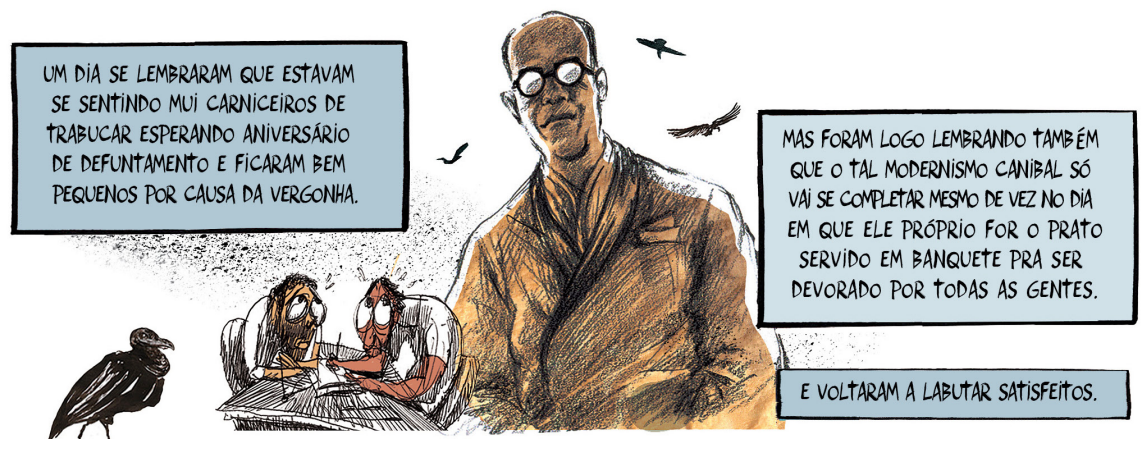

Fig. 7. Posfácio de Macunaíma em quadrinhos. Abu e X (2016, p. 77).

$\mathrm{Na}$ fala do narrador, encontra-se o argumento final da $\mathrm{HQ}$, como resultado exato do modernismo canibal. Assim, a própria antropofagia modernista passa a ser oferecida em banquete, bem como o conteúdo de Macunaíma em prosa. A Antropofagofagia é, portanto, esse ato sublime de devorar a antropofagia modernista, resultando em projetos que dialogam com outras temporalidades, espaços e formatos.

Em seus processos criativos, Angelo Abu e Dan X finalizam o posfácio com uma cena de comemoração em que os autores da rapsódia se encontram com Tarsila do Amaral, Mário de Andrade, Macunaíma (em primeiro plano), Jiguê, Maanape, Iriqui e Anita Malfati (ao fundo da imagem). Uma comemoração antropofagofagicamente elaborada. Assim, nas palavras do narrador: "E fizeram a festa comendo e dançando e alegrando com muitas pândegas liberdosas. E tudo acabou se fazendo a vida real". (ABU e X, 2016, p. 77).

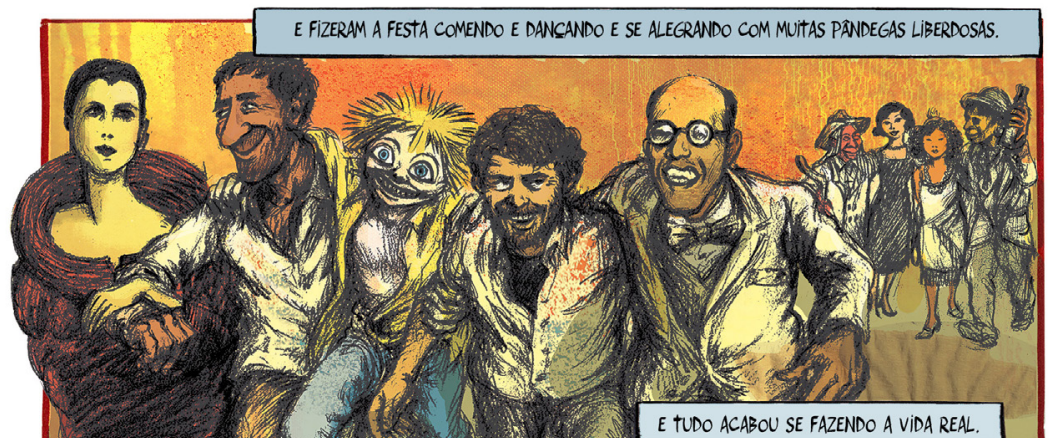

Fig. 8. Posfácio de Macunaíma em quadrinhos. Abu e X (2016, p. 77). 
A cena na Figura 8 remonta à prosa de Mário de Andrade em seu capítulo 'Macumba'. No interior da rapsódia andradiana, é sugerido um encontro comemorativo de nomes expoentes do modernismo:

E pra acabar todos fizeram a festa juntos comendo bom presunto e dançando um samba de arromba em que todas essas gentes se alegraram com muitas pândegas liberdosas. Então tudo acabou se fazendo a vida real. E os macumbeiros, Macunaíma, Jaime Ovalle, Dodô, Manu Bandeira, Blaise Cendrars, Ascenso Ferreira, Raul Bopp, Antônio Bento, todos esses macumbeiros saíram na madrugada. (ANDRADE, 2016, p. 92).

As personalidades são artistas plásticos, poetas e pesquisadores que Mário de Andrade estimava, sobretudo, pelo fato de terem abraçado o projeto modernista brasileiro. São representados na rapsódia gráfico-visual da seguinte maneira (Fig. 9):

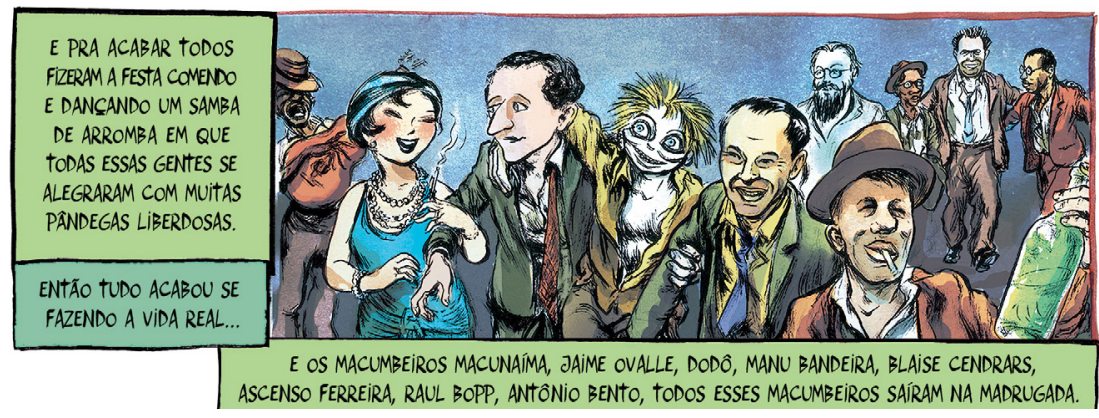

Fig. 9. Macunaíma em quadrinhos. Abu e X (2016, p. 49).

Em análise, nota-se a manutenção do texto verbal distribuído na legenda. Já na representação visual, os autores introduziram outros elementos e outros personagens à narrativa. Assim, a cena descrita por Andrade cita oito pessoas, ao passo que na imagem de Abu e X vemos dez personagens. Aqui, são acrescidos um homem tocando violão no canto esquerdo da imagem e uma mulher à sua frente, que não é identificada no texto. Todos compõem um quadro festivo na cena.

Observa-se que os autores da HQ no posfácio reproduzem a ideia de parte do texto de Mário de Andrade, presente no capítulo 'Macumba', para, igualmente à prosa, propor um grande encontro comemorativo com artistas modernistas (Tarsila e Anita), o autor da narrativa "Macunaíma" (Mário de Andrade) e parte de seus personagens (Macunaíma, Jiquê e Maanape), oferecendo ao leitor um caráter de realidade do encontro. Um elemento importante a ser ressaltado é que os autores da HQ, no posfácio, não exibem o nome das personagens presentes no quadro, ficando a cargo do leitor identificá-los.

A disposição dos personagens nos dois quadros trata de evidenciar as similaridades entre as duas cenas: Macunaíma centralizado; à direita, um casal de braços dados; 
à esquerda, dois homens, um deles tem o braço seguro por Macunaíma (comum às duas imagens); e, em segundo plano, quatro personagens. Outro aspecto relevante diz respeito às cores, que constituem elemento distintivo entre os dois quadros, sendo o plano de fundo do posfácio composto por tons diversos de alaranjados, ao passo que o cenário do encontro, em 'Macumba', é azul.

A partir das observações baseadas no posfácio, é possível concluir que Macunaíma em quadrinhos é uma obra fundamentada na expectativa modernista, já que apresenta, em sua elaboração, o princípio antropofágico das artes como estratégia distintiva, resultando, portanto, num produto formado por diversas formas de antropofagia, como apontamos aqui. Como ilustração, temos a influência e a reminiscência às obras de artes do período Modernista no interior da HQ.

Outro elemento que ilustra a vivacidade do projeto modernista na obra é a capa e a contracapa da rapsódia-gráfico visual. Ali, o grande acontecimento antropofágofágico é antecipado, atravessando a capa, a lombada e a contracapa da obra. Assim, já no contato com esses elementos, é possível enxergar a grande composição alegórica que se dará no interior da HQ (Fig. 10).

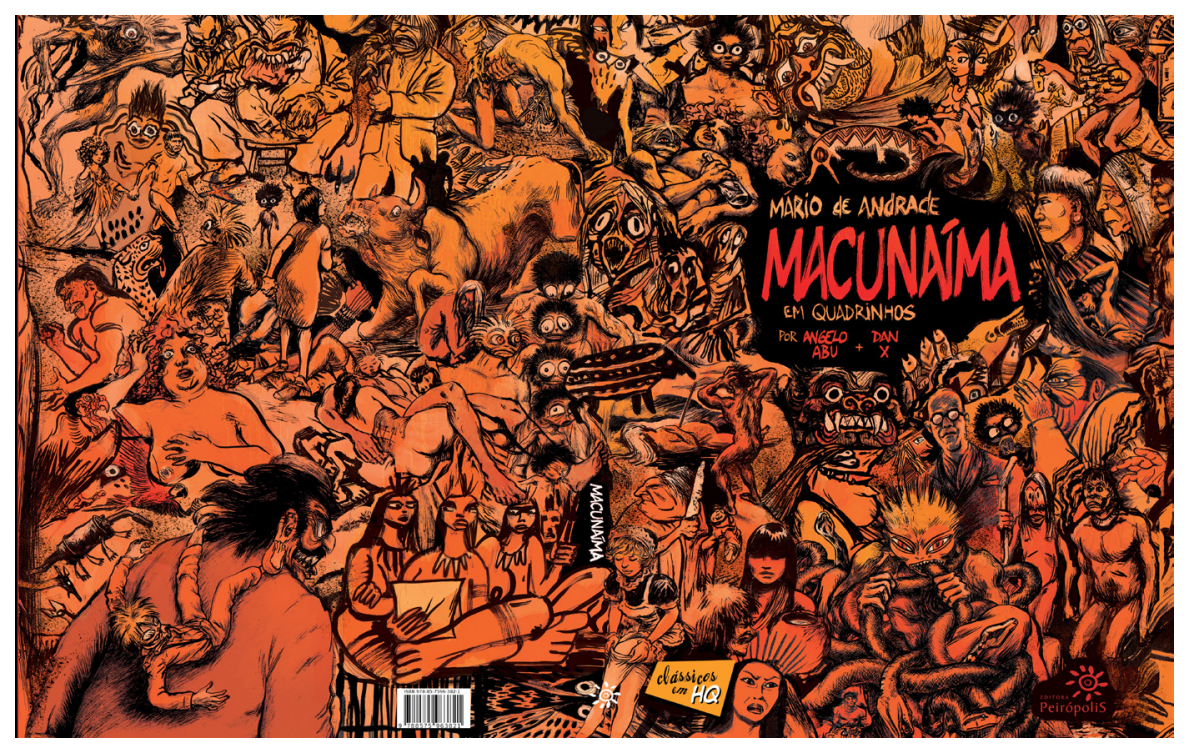

Fig. 10. Capa e Contra capa de Macunaíma em quadrinhos. Abu e X (2016).

\section{Considerações finais}

Prestes a completar noventa anos desde a sua primeira publicação, a rapsódia Macunaíma: um herói sem nenhum caráter revela, ainda hoje, sua pujança literária 
ao tornar-se objeto de apreciação em diferentes estudos. Nesse tempo, a obra seminal do Modernismo brasileiro foi traduzida para linguagens muito distintas do seu texto-fonte, como as artes visuais, o cinema e os quadrinhos.

Concentrando-nos na tentativa de entender o jogo de semiose, nesse texto analisamos os modos e formas com que o Modernismo brasileiro foi representado pelas mãos de Angelo Abu e Dan X, utilizando a linguagem quadrinística na HQ Macunaíma em quadrinhos. Desde o percurso adotado para a análise, com a opção teórico-metodológica da Tradução Intersemiótica, até chegarmos à análise, propriamente dita, apresentamos a HQ Macunaíma com base em seu caráter intersemiótico, pela via imagética, chamando a atenção para a sua condição antropofágica, reconhecível desde os primeiros passos da sua elaboração, como evidenciado no Posfácio da HQ.

Desse modo, afirmamos que a obra é uma rapsódia gráfico-visual antropofágica, que em seu interior assume os argumentos da antropofagia modernista ao propor uma composição gráfica, rica em cores fortes e apelativas, com tracejados estilísticos únicos e desenhos que causam no leitor certa inquietação e efeito de devoração pela via estética. A estética, aliás, tem lugar de destaque aqui. Ela nos leva a perceber a experiência visual peculiar da obra, ao inserir em suas páginas elementos que remetem tanto à prosa de Mário de Andrade, quanto à própria história do modernismo. Boa ilustração encontra-se na transcriação do cartaz da Semana de Arte Moderna de 1922 e das telas reeditadas para a HQ, como o Abaporu, de autoria da artista plástica modernista Tarsila do Amaral.

Ao reconhecermos a expressiva presença de traços de manutenção da proposta modernista em Macunaíma em quadrinhos, que, por sua vez, atribuem ao texto andradiano a identidade das histórias em quadrinhos, o fazemos considerando a tradução da prosa a partir de sistemas próprios às HQs, como a utilização de legendas, de balões e de onomatopeias, de figuras cinéticas, de caricaturas e de expressões corporais que somente as HQs conferem aos seus personagens.

Outro ponto a ser considerado como argumento antropofágico na HQ diz respeito às formas adotadas para a composição dos quadros, apresentadas em formatos diversos, que fazem com que não se possa tratar a obra como um produto homogêneo em seu conjunto. Pelo contrário, o que se percebe é um estilo que ostenta formas e cores diversas, como o próprio Modernismo propunha.

A partir das imagens elaboradas na $\mathrm{HQ}$, o leitor é reconduzido ao universo modernista, sendo apresentado a personalidades como Tarsila do Amaral, Carybé, Mário de Andrade, Manuel Bandeira, Raul Bopp e tantos outros que, ainda que indiretamente, dão legitimidade a Macunaíma em quadrinhos, com suas cores, seus textos e suas impressões artísticas, num período em que os quadrinhos ainda estavam se inserindo no Brasil.

Traduzida intersemioticamente para os quadrinhos, a prosa se torna ainda mais enriquecida, já que, ao olharmos as imagens nos deparamos com um universo distinto, em que traços e formas estéticas, muitas das quais disformes, nos falam de um personagem que, tal qual a identidade brasileira, parece estar ainda em processo de formação. 
Por fim, enfatizamos o esforço de intersecções e entrecruzamentos discursivos presentes em Macunaíma em quadrinhos, que operam a partir de signos visuais distintos, como a pintura, as ilustrações, as cores e a palavra escrita. Cada um, a seu modo, constitui significados específicos. Juntos, recriam a rapsódia modernista.

A Tradução Intersemiótica na HQ fortalece relações textuais capazes de produzir sentido e de reforçar a importância do texto-fonte, ao tempo em que também distingue, estrategicamente, a linguagem quadrinística e suas mensagens visual e verbal. Trata-se de uma forma diferente de narrar, contemplando outros saberes, outras técnicas, e, sobretudo, cruzando essas muitas possibilidades de expressão, que somente enriquecem o mundo repleto de linguagens, que mais dialogam do que divergem.

Ricardo Oliveira de Freitas é professor titular da Universidade do Estado da Bahia - UNEB; é doutor em Comunicação e Cultura, Universidade Federal do Rio de Janeiro - UFRJ.

ricofrei@gmail.com

Lucineide Magalhães de Matos é doutoranda no Programa de Pós-Graduação em Comunicação da Universidade Federal Fluminense - UFF.

lucineidematos@gmail.com

\section{Referências}

ABU, A. e X, D. Macunaíma em quadrinhos. São Paulo: Peirópolis, 2016.

AMARAL, T. O Batizado de Macunaíma. 1956. original de arte, óleo sobre tela, $132.5 \mathrm{~cm} \times 250$ cm. Coleção particular.

ANDRADE, M. de. Macunaíma, o herói sem nenhum caráter. $1^{a}$ ed. São Paulo: Penguin Classics Companhia das Letras, 2016.

Aspectos da literatura brasileira. São Paulo: Martins, 1974.

BOPP, R. Movimentos modernistas no Brasil 1922-1928 [recurso eletrônico]. Rio de Janeiro: José Olympio, 2012.

BOSI, A. Céu, inferno: ensaios de crítica literária e ideológica. São Paulo: Duas Cidades; Ed. 34, 2003.

BRASIL. Lei n. 9.610 de 19 de fevereiro de 1998. Altera, atualiza e consolida a legislação sobre direitos autorais e dá outras providências. Casa Civil. Presidência da República. Disponível em: <http://www.planalto.gov.br/ccivil_03/Leis/l9610.htm?TSPD_101_R0=df7eedf1dd49c65b2a73f908 e16fd9d4eU800000000000000002472b4b1ffff00000000000000000000000000005b22fd64005c 339b6f>. Acesso em: 13 jun. 2018.

CAMPOS, H. de. Metalinguagem \& outras metas. Petrópolis: Vozes, 2006. 
. Morfologia do Macunaíma. São Paulo: Perspectiva, 2008.

MACUNAÍMA. Direção: Joaquim Pedro de Andrade. Produção: Condor Film; Grupo Novo de Cinema e TV, 1969. 1 filme (50 min), son., color., 35mm.

PIGNATARI, D. Semiótica \& Literatura. São Paulo: Ateliê Editorial, 2004.

PLAZA, J. Tradução Intersemiótica. São Paulo: Editora Perspetiva, 2003.

RAMOS, P. A leitura dos quadrinhos. São Paulo: Contexto, 2016.

SANTAELLA, L. O que é semiótica. São Paulo: Brasiliense, 2012. (Coleção Primeiros Passos).

SELO LETRAS IN.VERSO E RE.VERSO. Macunaíma ilustrado por Carybé. Catálogo com ilustrações de Carybé para Macunaíma, de Mário de Andrade. Disponível em: <https://issuu.com/setefaces/docs/ as_ilustra es_de_caryb__para_ma>. Acesso em: 12 jul. 2016.

SOUZA, G. de M. e. O Tupi e o alaúde: uma interpretação de Macunaíma I. São Paulo: Duas Cidades; Ed. 34, 2003. 